\title{
PART IV: PRACTICE Improving Teaching and Learning
}

We come now to the practice of teaching improvement, the bread-and-butter of most faculty development programs. The articles in this section describe programs that range in purpose from training foreign teaching assistants to offering Supplemental Instruction without benefit of a "Supplemental Budget."

The first piece in this section details the training needs of faculty who find hearing-impaired students in their classes. The authors, Karen Conner and Harry Lang, describe a training model for institutions with small numbers of deaf students, and identify benefits for teaching quality in general resulting from participation in programs designed to improve teaching of the hearing impaired.

Many faculty development programs offer training for teaching assistants. Through such training, developers have an opportunity to socialize the next generation of faculty in the direction of valuing teaching skills and developing a good foundation for subsequent success as teachers. In this domain of practice, Jody Nyquist and Ann Staton-Spicer explore several unconventional but research-based strategies for developing presentation skills of teaching assistants; Rosslyn Smith and Len Ainsworth describe a program that has successfully responded to a major institutional need, helping foreign teaching assistants learn to communicate effectively with students in their classes.

Finally, we encounter the realities of academic life as experienced by a faculty member, Breck Peters, who wants to help his students do well in an intellectually challenging course, and who wants to offer them the benefits of Supplemental Instruction (SI), but whose department budget cannot provide the funds for a student "specialist" to conduct SI sessions. His solution won't suit all, but it will offer hope to those who doubt their students' capability for college level work. 